\title{
Heri Trotnow
}

\section{Informationen \\ Deutsch als Fremdsprache}

Herausgegeben von

Deutschen Akademischen Austauschdienst

in Zusammenarbeit mit dem

Arbeitskreis Deutsch als Fremdsprache beim DAAD

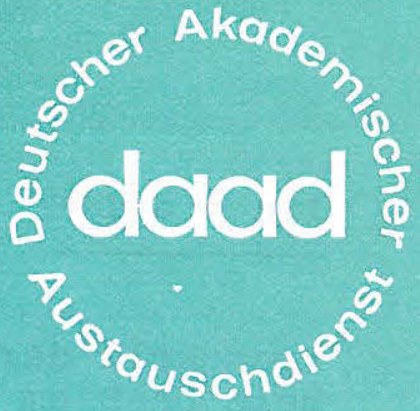

Kennedy-Allee 50, 5300 Bonn-Bad Godesberg 1, Telefon 88 21, Telex 0885515

$\operatorname{Nr} .7 / 1976$

13. Dezember 1976

Der Arbeitskreis Deutsch als Fremdsprache und der Deutsche Akademische Austauschdienst wünschen allen Lesern der 'Informationen Deutsch als Fremdsprache' ein frohes Weihnachtsfest und ein glückliches, erfolgreiches Jahr 1977!

\section{Hinweise:}

1. Die Jahrestagung DaF 1977 kann nicht, wie in Bremen beschlossen, in der Zeit vom 1. bis 3. Juni stattfinden, weil in dieser Woche in der Stadt Mainz keine Unterbringungsmöglichkeiten zur Verfügung stehen.

Neuer Termin:

Donnerstag, 9. Juni 1977 bis Samstag, 11. Juni 1977. ( siehe auch Seiten $9+10$ )

2) Die in Bremen beschlossene Fortbildungstagung zum Thema "Probleme des Deutschunterrichts für Lerner mit außereuropäischen Ausgangssprachen in heterogenen Gruppen" findet in der 2. Septemberhälfte 1977 in Freiburg statt. Nähere Einzelheiten werden baldmöglichst mitgeteilt. (siehe auch Seiten 8/13)

\section{Redaktion:}

Dr. Armin Wolff

Universität Regensburg

Universitätsstraße 31

8400 Regensburg

Tel.: $0941 / 9432436$
Joachim Hoffmann

DAAD

Kennedyallee 50

5300 Bonn-Bad Godesberg

Tel. : o2221/8821
Dr. Gabriele Neuf-Münkel Studienkolleg an der Universität Bonn Mechenstraße 37, Bonn Tel.: o2221/239436

Das Informationsblatt soll für den Bereich DaF ein Forum begründeter Meinung sein; die mit Verfassernamen gekennzeichneten Beiträge stellen dabei nicht unbedingt die Meinung äes Arbeitskreises oder des DAAD dar. 